\title{
Desulfovibrio fairfieldensis
}

National Cancer Institute

\section{Source}

National Cancer Institute. Desulfovibrio fairfieldensis. NCI Thesaurus. Code C86341.

A species of anaerobic, Gram neg ative, rod shaped bacterium assigned to the phylum Proteobacteria. This species is motile, catalase positive, oxidase, urease and indole negative, produces hydrogen sulfide and is asaccharolytic. D. fairfieldensis is a commensal organism of the intestinal tract and is rarely seen to cause clinical disease. 